\title{
Self-Fulfilling Prophecy and the Future of Doping
}

\author{
Stephen Moston ${ }^{1}$ \\ Terry Engelberg ${ }^{2}$ \\ $\&$ \\ James Skinner ${ }^{2}$
}
${ }^{1}$ Centre for Applied Psychology, Faculty of Health, University of Canberra, Bruce ACT 2601, Australia
2. Department of Tourism, Sport and Hotel Management, Griffith Business School, Parklands Drive, Griffith University, Gold Coast QLD 4111, Australia.

Contact author: Terry Engelberg

Phone: (+61 755527675$)$

Email: t.engelberg@griffith.edu.au 


\begin{abstract}
Objectives: Surveys of the perceived incidence of doping in sport suggest that such behaviour is relatively common. Perceptions may potentially be of greater significance than actual incidence: athletes who believe that other athletes are doping may be more likely to engage in such practices, potentially creating a damaging self-fulfilling prophecy.

Design: A cross-sectional study examines the effects of age (range 12-17 years), gender and involvement in sport (elite athletes and non-athletes) on the perceived incidence of doping. A measure of moral functioning was included as a covariate.

Method: 312 participants were asked to estimate the incidence of doping in elite sport, to name a sport they believed in which doping was most prevalent, and to complete a short survey assessing level of moral functioning and demographic characteristics.

Results: The overall estimated incidence of doping was $28.8 \%$, with athletics, weightlifting and cycling named as the sports in which doping was perceived to be most prevalent. Perceived incidence data were analysed using a 3 (age group: 12-13, 14-15, 16-17) x 2 (gender) $\mathrm{x} 2$ involvement in elite sport (non-athletes, elite athletes) ANACOVA, with the covariate of moral functioning. There were significant effects of both age group and gender on estimates of doping. Involvement in sport was not linked to perceived incidence. There was a significant (negative) relationship between moral functioning and estimates of doping. Conclusions: Findings are discussed in relation to the potential diffusion of doping behaviours and the content of anti-doping initiatives, such as attempting to counter doping through teaching the 'morality of sport'.
\end{abstract}

Keywords: incidence, expectancies, moral functioning, sport, athletes 


\section{Self-Fulfilling Prophecy and the Future of Doping}

In psychology it has long been recognised that expectancies, be they true or false, can shape reality (e.g., Merton, 1948; Rosenthal \& Jacobson, 1968; Snyder, 1984). False expectancies have proven to be a particularly intriguing area of research, in large part because of their potential for harm, but also because they are often widely shared and stubbornly resistant to change (Miller \& Turnbull, 1986).

False expectancies are capable of causing behavioural changes (in both the perceiver and the target), that lead to their own fulfilment: a process known as a self-fulfilling prophecy (Merton, 1948). Merton (1948, p.195) offered the following definition:

The self-fulfilling prophecy is, in the beginning, a false definition of the situation evoking a new behavior which makes the originally false conception come true. The specious validity of the self-fulfilling prophecy perpetuates a reign of error. For the prophet will cite the actual course of events as proof that he was right from the very beginning.

For example, a sporting coach may underestimate an athlete's talent, believing that the athlete is less capable than the athlete truly is. The coach then spends less time with the athlete and as a consequence the athlete's performance suffers. The coach then uses the poor performance as a justification for having spent little time with that athlete.

There have been a large number of empirical studies by psychologists on the mechanisms and power of self-fulfilling prophecies (Madon, Willard, Guyll, \& Scherr, 2011). Most have focused on the educational implications of self-fulfilling prophecies, where for example, a teacher's false beliefs about a seemingly poor student might result in the teacher spending less time with that student, ignoring their contributions in class, and generally behaving in a way that ultimately fulfils the initial false belief (e.g., Rosenthal, 1973). 
As well as impacting on the individual, Rosenthal and Jacobson (1968) suggested that self-fulfilling prophecies could create widespread social problems by accumulating over time. The magnitude of a perceiver's self-fulfilling prophecy becomes stronger as it is repeated and reinforced. Madon et al. (2011) argue that accumulation also occurs when the number of people holding a false belief increases. In sum, a false belief that is repeated over time and/or widely shared, can theoretically generate a self-fulfilling prophecy that results in the validation of the initial false belief. However, it should be noted that Jussim and Harber (2005) argued that self-fulfilling prophecies may actually dissipate over time rather than accumulate. This might occur either because the person who is the target of an expectancy becomes aware of the false expectation and seeks to influence the perceptions of others (i.e., the perceivers), or because exposure refutes incorrect perceptions. In short, self-fulfilling prophecies do not inevitably fulfil themselves (Miller \& Turnbull, 1986). Merton (1948; p.196) called this process a self-disconfirming prophecy, or more dramatically: a "suicidal prophecy".

Counterpart of the self-fulfilling prophecy is the "suicidal prophecy" which so alters human behavior from what would have been its course had the prophecy not been made, that it fails to be borne out. The prophecy destroys itself (p.196)

One social problem where a self-fulfilling prophecy may be occurring is doping in sport. It will be argued that there is a gap between the officially observed level of doping in sport, and perceptions of such behaviour. Athletes, members of the public and even academic experts (e.g., Cashmore, 2012; Kayser \& Broers, 2012), clearly express beliefs that doping is highly prevalent: that is, widespread doping is prophesised. What is not yet known is the extent to which young people (both athletes and non-athletes) share similar expectancies. If they do, then doping is effectively becoming normalised at an early age which may well 
result in the fulfilment of the prophecy as the expectancy of doping is reinforced throughout the developmental pathways of young people.

\section{Genesis of a social problem}

Doping has now taken centre stage as one of the most significant problems threatening the integrity of sport (Australian Crime Commission, 2013). In the last few years there has been a constant stream of media reports highlighting doping by elite athletes. Psychologists and others have conducted studies attempting to determine the incidence of doping (e.g., Jalleh \& Donovan, 2008; Waddington, Malcolm, Roderick, \& Naik, 2004) and the psychological characteristics of doping athletes (e.g., Gucciardi, Jalleh, \& Donovan, 2011; Wiefferink, Detmar, Coumans, Vogels, \& Paulussen, 2008).

Doping controls were initially conceived to address the problem of performance enhancing drug (PED) use by athletes. In the 1970s and 1980s the use of PEDs was increasingly being linked to the deaths of elite athletes, mainly cyclists (Verroken, 2000). As a direct response to these problems, and to assist in the international standardisation of antidoping efforts, in 1999 the World Anti-Doping Agency (WADA) was created. WADA then developed the first World Anti-Doping Code (WADA, 2003), which periodically undergoes revisions. The current edition (WADA, 2009) will be superseded by the third edition, which will come into effect in 2015.

Doping is defined in terms of the occurrence of one or more of the eight anti-doping rule violations specified in the World Anti-Doping Code (WADA, 2009). This includes, for example, violations such as the presence of a prohibited substance or its metabolites or markers in an athlete's bodily specimen; and refusing, or failing without compelling justification, to submit to sample collection after notification; possession of prohibited substances and methods. Doping is not restricted to the use of PEDs, it now includes other 
illicit ('recreational') drugs that are generally not performance enhancing (except in very specific circumstances) but are potentially a threat to health, or are seen as contrary to sporting values.

\section{How prevalent is doping?}

In 2011 WADA laboratories analysed 243,193 biological samples (WADA, 2012). Adverse analytical findings were found in $1.2 \%$ of cases. Some of these adverse findings were subsequently deemed not to be rule violations since the athletes had 'therapeutic use exemptions'. Biological testing, usually in the form of urine analysis, by anti-doping agencies typically reveals that about $1-2 \%$ of athletes are doping, however many suspect that the majority of athletes that are identified through this testing process are accidental and occasional users. A study by Sottas et al. (2011), in which the blood samples of over 7,000 athletes were analysed, revealed that an average of $14 \%$ of athletes (range of 1-48\% depending on the specific sport) were doping, suggesting that blood testing may be a far better detection tool than urine analysis. Former WADA President Dick Pound acknowledged that the small number of athletes who are caught by anti-doping agencies, was an underestimation (Sports Illustrated, 2012). Asked to estimate the true incidence of doping, Pound said: "It's north of 10 and short of 90 [\%], but it's more than people expect".

There have been a large number of social science research studies attempting to generate data on the incidence of doping, however methodological or sampling limitations hinder the interpretation of such data. For example, there have been several attempts (Ama, Betnga, Moor, \& Kamga, 2003; Goulet, Valois, Buist, \& Cote, 2010; Ozdemir et al., 2005; Spence \& Gauvin, 1996; Thomas, Dunn, Swift, \& Burns, 2011) to assess the incidence of doping through self-report survey-type methodologies. This approach generates estimates of 
incidence between 1.6 and 77.8\% (Pitsch \& Emrich, 2011), depending on the range or type of doping behaviours under examination, as well as the populations featured.

Self-report methodologies have been extensively criticised (Pitsch \& Emrich, 2011; Striegel, Ulrich, \& Simon, 2010), with the prevailing criticism being that self-report methodologies are subject to bias and thereby likely to under-estimate the incidence of doping. However, alternative research methods, such as randomised response techniques (Striegel, Simon, Hansel, Niess, \& Ulrich, 2006; Striegel et al., 2010) have typically fared little better, producing an equally diverse range of estimates of incidence, from $7 \%$ to $48 \%$ (for a review see Pitsch \& Emrich, 2011).

The diverse research findings can in part be explained by the inconsistent use of definitions (e.g., 'doping' vs. 'performance enhancing drug use' vs. specific named substances, such as 'anabolic steroids') and types of question used (e.g., 'ever used' vs. 'used in the last 12 months'). Despite the varied samples and methodologies, it is clear that the estimated incidence of drug use by athletes from surveys and randomised response techniques typically exceeds the estimates from laboratory analyses.

Not surprisingly then, there is considerable uncertainty over the true extent of doping. Instead of valid data, the key stakeholders, including athletes, sports administrators, antidoping agencies and the public (the consumers of sport), must base their beliefs on a seemingly never-ending succession of media reports and confessional autobiographies (e.g., Agassi, 2010; Hamilton \& Coyle, 2012). One obvious danger here is that if an athlete perceives that the majority of their competitors are using banned substances then they may be more likely to engage in such behaviour, thereby fulfilling the prophecy.

\section{The perceptions of athletes}


There have been several attempts to gauge the perceptions of athletes about the incidence of doping. In England, Waddington et al. (2004) surveyed 706 football (soccer) players. Nearly half of the sample stated that no players used PEDs and about a third estimated incidence at $2 \%$ or greater. In Australia Jalleh and Donovan (2008) report that about a third of athletes estimated incidence of doping as between $1 \%$ and $9 \%$, with another third giving even higher estimates. Also in Australia, Dunn et al. (2009) surveyed 974 elite Australian athletes. The participants were asked to provide estimates of 'illicit drug' use for their own sport, and for 'athletes in general' (i.e., all sports combined). About a third estimated incidence at $2 \%$ or lower; the remaining participants offered higher estimates. Estimates for 'own sport' were lower than those for 'all sports'.

Unfortunately, integrating the above findings is impossible as each used different definitions and response options. Nevertheless, the one recurring theme is that large numbers of elite athletes see the incidence of doping as being far more prevalent than the official doping statistics would suggest.

\section{The perceptions of non-athletes}

Opinion surveys of the views of non-athletes are extremely rare. This is a particularly curious omission as it is ultimately the opinions of the public that anti-doping agencies are most eager to influence. Whilst the laudable goal of safeguarding the health of athletes initiated the current anti-doping movement, it would be fair to say that the driver that keeps it going is public opinion. For example, in both the USA and Australia, sport is recognised as a powerful cultural force and protecting the integrity of sport against threats such as matchfixing and doping is a national priority (Australian Sports Commission, 2012; USADA, 2011). 
As with the data from athletes, the scant literature on public opinion on doping suggests that doping is perceived to be relatively common. In Switzerland, according to the Swiss Laboratory for Doping Analyses (2010), the detected rate of doping is about $2.5 \%$, yet nearly three quarters of adults estimated the incidence level in elite sport as greater than $10 \%$ (Nocelli, Kamber, Francois, Gmel, \& Marti, 1998; Stamm, Lamprecht, Kamber, Marti, \& Mahler, 2008). There were some consistent links between the age and gender of the respondent and opinions, with for example, the younger respondents showing greatest support for liberalization (Stamm et al., 2008) and women more likely to recognise that doping might bring mental health problems (Nocelli et al., 1998).

In Australia there has only been one comparable study of public opinion. Moston, Skinner, and Engelberg (2011) asked a large, representative sample of adult non-athletes to estimate the incidence of PEDs. The mean estimated incidence of PED use was $26 \%$ (females gave higher estimates than males, and estimates correlated positively with age). Respondents were also asked to identify sports in which PEDs were most commonly used. The three sports named as most commonly using PEDs were weightlifting, cycling and athletics.

\section{The present study}

Studies of perceptions of doping are relatively scarce. Within this scant literature one population that has not yet been studied is young people, neither athletes nor non-athletes. In many ways this omission is not surprising as anti-doping interventions typically only target elite adult athletes. Nevertheless, it is a serious omission and there are several pressing reasons for a study of young people's perceptions of the extent of doping.

First, it is now widely recognised that prevention, rather than detection, remains the best strategy for eliminating drug use in sport (Lippi, Franchini, \& Guidi, 2007). There is a 
considerable body of evidence showing that some athletes as young as 11 or 12 years of age use performance enhancing drugs (Johnston, O'Malley, Bachman, \& Schulenberg, 2013; Laure \& Binsinger, 2007; Rees, Zarco, \& Lewis, 2007). Consequently, if prevention is to be effective it must target athletes before they start doping. According to Stamm et al. (2008) support for liberalisation is highest amongst young people. This means that young athletes should be the focus for preventative interventions.

Second, understanding the beliefs of young people is important as this may give an insight into the future of doping in sport. A stated goal of anti-doping legislation is "To protect the Athletes' fundamental right to participate in doping-free sport and thus promote health, fairness and equality for Athletes worldwide" (WADA, 2009; p.3). However, there are many who publicly challenge such a goal and advocate for the legalisation of doping (e.g., Cashmore, 2012; Kayser \& Broers, 2012; Kirkwood, 2009; Smith \& Stewart, 2008). Part of the rationale for this anti-anti-doping movement is a belief that doping is already so widespread that past attempts to deter doping should be declared as failures, with little hope that future initiatives will fare any better. With such a fatalistic backdrop in mind, it is to be expected that doping will be seen as highly prevalent, certainly much higher than the official statistics would suggest. This may set the foundation for a possible self-fulfilling prophecy: if young people perceive that doping is a common and accepted practice they may alter their own behaviour accordingly. In essence: 'In order to win, I need to use PEDs. Everyone already thinks I am using PEDs, so I might as well do it'.

\section{Hypotheses}

Based on the previous studies of perceptions of doping, it is hypothesised that there will be an age related effect on opinion (estimates of incidence increasing with age), and a 
gender effect: females offering higher estimates than males. It is also hypothesised that involvement in sport will impact on estimates: athletes offering higher estimates than nonathletes.

In addition to the above hypotheses, we also hypothesised that level of moral development would be related to estimates of incidence of doping. Research has shown how level of moral functioning, a concept based on Rest's (1984) model of moral action, relates to a range of real and hypothetical sporting behaviours, including aggression, sportspersonship and beliefs about fair play (e.g., Bredemeier \& Shields, 1986; Gibbons, Ebbeck, \& Weiss, 1995; Kavussanu \& Roberts, 2001; Kavussanu, Roberts, \& Ntoumanis, 2002: Ommundsen, Roberts, Lemyre, \& Treasure, 2003). Efforts to understand why some people use PEDs have begun to centre on how morality relates to the use of PEDs (e.g., Kaye \& Boardley, 2012; Lucidi et al., 2008). In this study we hypothesised that that there would be an inverse relationship between level of moral functioning and perceptions of the incidence of doping.

\section{Method and Materials}

\section{Participants}

There were 312 participants in the study, all recruited from sporting clubs and a high school in Queensland, Australia. Main demographic characteristics of the sample (gender, age group and involvement in sport) are shown in Table 1. Participation in competitive sport was defined as participation at regional levels or higher (e.g., inter-state and international competition). There were approximately equal numbers of athletes and non-athletes in each age group.

The main sports represented included rowing (16.0\%), netball (14.7\%), rugby union (12.0\%), football (soccer) (11.3\%), rugby league (5.3\%) and Australian Rules Football (AFL) $(5.3 \%)$. Other sports played by less than $5 \%$ of the participants included athletics, basketball, 
cricket, cycling, gymnastics, hockey, judo, swimming, taekwondo, tennis, volleyball, water polo, triathlon, table tennis, horse riding and fencing.

INSERT TABLE 1 ABOUT HERE

\section{Measures}

Perceived incidence of performance enhancing drug use in sport. Participants were asked to estimate the incidence of PED use in sport ('In your opinion, what percentage of elite and professional athletes in all sports use performance enhancing drugs?'). Participants were also asked (open question) to name a sport in which they thought that the use of PEDs by elite athletes was common. Athletes (only) were also asked to estimate the incidence of PED use in their own sport.

Moral functioning. According to Rest (1984), once a person has identified that a behaviour may impact on the welfare of others, a process of judgement (determining what ought to be done) and intention (deciding what one intends to do) will shape subsequent behaviour. The joint process of judgement and intention is collectively referred to as moral functioning (e.g., Kavussanu \& Roberts, 2001). In research studies of moral functioning, participants typically read a fictitious scenario and then indicate how appropriate the behaviour in question is (judgment) and are then asked whether they would engage in the behaviour (intention) (e.g., Kavussanu \& Roberts, 2001; Kavussanu et al., 2002; Kavussanu \& Spray, 2006; Ommundsen et al., 2003).

For the purpose of the present study, we developed a single PED use in sport scenario. This scenario was chosen as one that all young athletes and non-athletes could easily understand and identify with. Participants were asked to read the following:

Imagine that you are an athlete competing at an elite level. While you have been performing well, it is unlikely that your level of performance will be enough to get you to the finals. One option is to start a course of 
performance enhancing drugs that could radically improve your sporting performance.

Moral judgment, was measured by asking all participants to consider the above scenario and to judge whether it was 'Never', 'Sometimes', or 'Always' appropriate to use PEDs. To assess moral intention, participants were asked to indicate whether they would 'Never', 'Sometimes', or 'Always' engage in PED use.

\section{Procedure}

Athletes. Approval to contact the athletes was sought from a senior member of each club. Once this was obtained, an informed consent letter was distributed to parents who were required to sign and return the letter to allow their child to participate in the study. Players whose parents had given consent for them to participate were approached during training sessions. Players were informed that the purpose of the study was to assess attitudes towards doping in sport and that their participation was voluntary and anonymous. Completed questionnaires were placed in envelopes and then placed in a sealed box (typically located near the clubhouse or other secure locations). Once all the questionnaires were collected, participants were debriefed as a group and thanked for their participation.

Non-athletes. The recruitment of non-athletes was similar to that of the athletes (using the same consent protocols), but instead of sporting clubs, non-athletes were recruited from a single high school.

Ethics. Ethics approval for the conduct of the study was granted by the Human Research Ethics Board of the first author's university.

\section{Results}

\section{Pre-analysis treatment of data}


Mean moral functioning was calculated by summing and dividing responses to the two moral functioning questions. The Cronbach's Alpha for this two item scale was .80. The range of possible scores was 2 to 6 , with higher scores denoting lower levels of moral functioning. Results for moral functioning by the key demographics are shown in Table 1.

Moral functioning data were analysed using a 3 (age group: 12-13, 14-15, 16-17) x 2 (gender) x 2 involvement in elite sport (non-athletes, elite athletes) ANOVA with mean moral functioning as the dependent variable. There were no significant differences with any of the three independent variables (all comparisons $\mathrm{p}>.05$ ).

\section{Perceived incidence of performance enhancing drug use in sport}

The mean estimated incidence of PED use in sport (all participants) was $28.84 \%$ (SD $=20.51$; range $0-100 \%)$. For athletes there were only minimal differences in perceived incidence by each of the main sports represented in the study. Rugby league players had the highest perceived incidence (29.90\%), followed by netballers $(29.36 \%)$, soccer players $(27.00 \%)$ and rowers $(26.90 \%)$.

Data were analysed using a 3 (age group: 12-13, 14-15, 16-17) x 2 (gender) x 2 involvement in elite sport (non-athletes, elite athletes) ANACOVA with the covariate of moral functioning, and the dependent variable of perceived incidence of doping (corrected model $F(24,311)=2.45 p<.001$; partial eta squared .17). Means $(\mathrm{M})$ and standard deviation (SD) scores for perceived incidence by each of the three independent variables are shown in Table 2.

\section{INSERT TABLE 2 ABOUT HERE}

There was a significant main effect for gender $(F(1,311)=5.65 p<.05$; partial eta squared $=.14)$ and age group $(F(2,311)=7.59 p<.001$; partial eta squared $=.07)$. There was no main effect for involvement $(F(1,311)=.01 p>.05$; partial eta squared $=.00)$. There was a 
significant effect of the covariate of moral functioning $(F(1,311)=6.04, p<.05$; partial eta squared $=.017)$.

The frequency of different estimates of incidence of PED use are summarised in Table 3. Approximately $88 \%$ of the participants gave estimates in excess of $10 \%$ and about $20 \%$ gave estimates of $50 \%$ or higher.

\section{INSERT TABLE 3 ABOUT HERE}

The sports most commonly identified as those in which doping was common included: athletics ( $n=105,33.7 \%)$; weightlifting $(n=66,21.2 \%)$; cycling $(n=29,9.3 \%)$; swimming ( $n=22,7.1 \%)$; and rugby league $(n=20,6.4 \%)$. Other sports identified (each less than 3\% of the sample) included: American football, Australian football league (AFL), baseball, boxing, cricket, football/soccer, gymnastics, hockey, judo, netball, rowing, rugby union, softball, surfing, taekwondo, tennis, yachting and water polo.

Athletes were also asked to estimate the percentage of elite and professional athletes in their own sport use that use PEDs. Across the entire sample of athletes $(n=151)$ the perceived incidence of PED use 'in own sport' was $11.26 \%$ (less than half of the perceived incidence across all sports). Data were examined using a 2 (gender) x 3 (age group) ANACOVA, with the covariate of moral functioning, and perceived incidence of doping in own sport as the dependent variable (corrected model $F(12,148)=1.61 p<.001$; partial eta squared .12). There was no significant effect for gender $(F(1,136)=.17 p>.05$; partial eta squared $=.00)$, or the covariate of moral functioning $(F(1,136)=.03 p>.05$; partial eta squared $=.00)$. There was an effect of age group $(F(5,136)=2.67 p>.05$; partial eta squared $=.09)$. Athletes aged 12-13 $(\mathrm{M}=15.28 ; \mathrm{SD}=12.86)$ and those aged $16-17(\mathrm{M}=15.27 ; \mathrm{SD}=13.98)$ estimated incidence of PED use in their own sport as higher than those aged 14-15 years (M $=12.22 ; \mathrm{SD}=10.79)$. 
Both netball and soccer players gave very low 'own sport' estimates $(7.25 \%$ and $10.01 \%$ respectively), with rugby league players $(13.73 \%)$ and rowers $(14.91 \%)$ giving higher own sport estimates. Due to small samples, data on perceived incidence in own sport were not statistically analysed.

\section{Discussion}

\section{Summary of findings}

The mean estimated incidence of PED use in sport was $28.84 \%$. As hypothesised, the current study found a gender effect (higher perceived incidence by females). There was also an age effect but not in the hypothesised direction: in this study estimates declined with age. Surprisingly, there was no effect of involvement in sport, but the covariate of moral functioning was (inversely) associated with estimates of PED incidence.

The estimates of PED use within 'own sport' were considerably lower than the estimates for all sports. While there were some variations in estimates of incidence by sport, estimates of incidence within 'own sport' were generally less than half those for 'all sports'.

\section{Prophecy or reality?}

The mean estimated incidence of PED use in sport was $28.84 \%$. This figure is slightly higher than that (26\%) reported for adult non-athletes (Moston et al., 2011). Due to the differences in response options, it is not possible to directly compare the current results to those from other studies. Nevertheless, the general trend in results is the same: PED use is perceived to be relatively common, a finding that is potentially of great significance. As described earlier, the official estimates of doping (from anti-doping control testing) suggest that doping is relatively rare, whilst social science research tends to suggest far higher rates of doping. It is thus clearly impossible to know whether the estimated incidence in this study is 
accurate or inaccurate. If we assume that the lower (anti-doping testing) estimates are accurate, then the high perceived incidence in this study is a concern. The expectation that doping is prevalent lays the groundwork for the development of a self-fulfilling prophecy whereby doping could become highly prevalent in the near future.

An alternative perspective is that the estimates in this study are potentially correct (i.e., about $29 \%$ of athletes really are doping) and the samples of athletes and non-athletes are remarkably well-informed on doping matters. If this estimate is correct, then it is highly likely that the next generation of athletes will be likely to adopt doping in the near future. That is, their awareness of the prevalence of doping creates an expectancy (doping is required) that also results in the widespread adoption of doping. The fact that non-athletes also saw doping as highly prevalent would support the adoption of future doping in either of these scenarios.

While self-fulfilling prophecies are not inevitably fulfilled (Jussim \& Harber, 2005), there is little reason for any optimism that the prophecy will dissipate. Jussim and Harber had suggested that prophecies can dissipate when the perceived person seeks to assert an alternative set of expectations, or through increased contact. In the case of athletes, sporting authorities and anti-doping organisations undoubtedly try to convey an anti-doping message, although the frequency with which athletes are then caught doping, mitigates against any such message. The continued doping behaviours of elite athletes and the widespread publicity given to such conduct suggests that the prophecy stands a far greater chance of succeeding rather than dissipating, or otherwise becoming what Merton called a 'suicidal prophecy'.

\section{False consensus or social projection?}

The high perceived incidence of PED use in all sports, but lower in own sport, is also of significance. Research (Petróczi, Mazanov, Nepusz, Backhouse, \& Naughton, 2008) has 
shown that athletes who are using drugs tend to offer higher estimates of drug use than nonusers. This finding has been interpreted in one of two ways. First, it may be a type of 'false consensus effect' (Ross, Greene, \& House, 1977), which occurs when individuals overestimate the extent to which others behave the same way as they do. According to this principle, athletes who are using drugs are likely to over-estimate the extent to which similar others (i.e., other athletes) behave as they do. A second explanation invokes the idea of social projection (James, Nepusz, Naughton, \& Petróczi, 2013; Petroczi et al., 2010), where doping athletes might deliberately under-estimate the incidence of doping in their own sport so as to give the impression that they are not doping. This particular behaviour, whatever the underlying cause, has potential scope as part of a tool to detect doping behaviours through forensic investigative interviewing (Stipis, 2010).

Young athletes and non-athletes shared similar views on the incidence of PEDs, Given that relatively few young people will have first-hand experience of behaviours such as PED use (Johnston et al., 2013; Laure \& Binsinger, 2007; Rees et al., 2007), it is likely that any expectancies about such behaviour will have been shaped by the media. This is likely to be problematic as the media probably over-represent the scale of PED use in sport. Reporting is also highly likely to be subject to common media distortions that rely on stereotypes. For example, demonised 'others' (Hinds, 2007) such as Chinese swimmers, use PEDs, but local athletes do not.

The media's interest in doping may thus result in a widespread acceptance of the reality of such representations, a situation which may then generate a self-fulfilling prophecy. This may be achieved through two distinct processes. First, as Rosenthal and Jacobson (1968) suggested, the erroneous belief is repeated and reinforced. Even the youngest participants in this study saw PED use as widespread. While there was a slight decline in perceived 
incidence with age, this finding means that young athletes (and non-athletes) carry such expectancies with them through an extended period of time. The erroneous belief thus has ample opportunity for repetition and reinforcement. Second, as Madon et al. (2011) suggested, if an erroneous belief is widespread this facilitates the fulfilment of a prophecy. The vast majority of the participants offered incidence estimates that were higher than the official statistics would suggest.

The task of anti-doping agencies is to both detect and deter doping in sport. Detection takes the form of urine and blood testing. These detection systems are then part of a deterrence strategy, effectively saying 'we will catch you'. The apparent ability of doping athletes to evade such detection renders this deterrence strategy as unconvincing, and so deterrence also includes anti-doping education. One of the most curious aspects of antidoping education is that it has little theoretical grounding, making it little different from earlier failed anti-drug campaigns, such as the 'Just say "No'" campaigns (Denham, 2011). The present study suggests that if (as expected) anti-doping education continues, then it will need to address the perception that doping is widespread, thereby directly challenging the self-fulfilling prophecy that appears to be in place. The study also suggests a possible theoretical direction for anti-doping education, specifically, the importance of teaching athletes about the 'morality of sport'.

\section{Moral functioning}

The current study showed that moral judgment was related to perceived incidence in the predicted direction: higher levels of moral judgement were correlated with lower estimates of PED use. These results support the research literature (e.g., Kaye \& Boardley, 2012; Lucidi et al., 2008) on the links between morality and doping in sport and raise a 
similar set of possible applications of the findings. Whilst the screening out of athletes deemed low in levels of moral functioning is an unlikely scenario, there is some scope for the development of educational programs to instil higher levels of moral functioning, which may in turn impact on the usage of PEDs. For example, Gibbons et al. (1995) showed that moral training (through the 'Fair Play for Kids' curriculum) improved the moral development of elementary school children. Whilst this is somewhat tenuous evidence for the utility of such an approach with elite adult athletes, a training curriculum that incorporates aspects of moral training might be feasible with younger development athletes.

\section{Limitations and future research}

There are some limitations of the current study that should be acknowledged. The foremost limitation is that there was only a single question on perceived incidence of PED use across all sports. This omits other illicit (recreational) drugs that are technically still a form of doping (albeit, one that is not usually performance enhancing) and which may be highly prevalent in some sports. In addition, the study did not seek to establish the origins of beliefs about the prevalence of doping. The absence of any significant difference between athletes and non-athletes suggests that it is not sporting participation per se that underlies the development of such beliefs. Instead, broader societal trends (e.g., media exposure) may be a more fruitful line of future investigation.

\section{Conclusion}

The findings of the present study show that young athletes and non-athletes see the use of PEDs by athletes as very common. However, the young athletes did not see their own sports as having such high levels of PED use. While it would be tempting to assume this perception reflects some positive personal experiences (the young athletes have not personally encountered PED use), such a view would probably be erroneous. Instead, the 
findings suggest that young athletes are essentially naive about the true extent of PED use. Anti-doping education might prove to be effective provided it acknowledges and addresses prevailing perceptions about the widespread use of such drugs. Sports where doping is perceived to be common and also feature large numbers of junior participants (athletics, swimming and rugby league are the obvious examples) should probably be targeted first. It is also possible that education campaigns that focus on moral education might positively impact on subsequent doping behaviours, although any such messages would need to be reinforced throughout the sporting industry, including support personnel such as administrators and coaches. 


\section{Acknowledgements}

This study was part of a larger project entitled "The relationship between moral code, participation in sport, and attitudes towards performance enhancing drugs in young people" and funded by the World Anti-doping Agency (WADA). 


\section{References}

Agassi, A. (2010). Open: An autobiography. New York, NY: Vintage.

Ama, P.F.M., Betnga, B., Moor, V.J.A., \& Kamga, J.P. (2003). Football and doping: study of African amateur footballers. British Journal of Sports Medicine, 37(4), 307-310. doi: 10.1136/bjsm.37.4.307

Australian Crime Commission (2013). Organised crime and drugs in sport: new generation performance and image enhancing drugs and organised criminal involvement in their use in professional sport / Australian Crime Commission (pp. ii, 45 p): Canberra: Australian Crime Commission, 2013.

Australian Sports Commission (2012). The essence of Australian sport. Canberra, Australia: Australian Government. Retrieved from http://www.ausport.gov.au/_data/assets/pdf_file/0011/312869/A4_brochure_7_05V5.pdf

Bredemeier, B.J., \& Shields, D.L. (1986). Athletic aggression: An issue of contextual morality. Sociology of Sport Journal, 3, 15-28.

Cashmore, E. (2012). Opinion: It's time to allow doping in sport. CNN, October 24, 2012. Retrieved from http://edition.cnn.com/2012/10/23/opinion/cashmore-time-to-allowdoping-in-sport/index.html

Cohen, S. (1972). Folk devils and moral panics: The creation of the mods and rockers, ( $3^{\text {rd }}$ ed.). London, England: Routledge.

Denham, B.E. (2011). When science, politics, and policy collide: On the regulation of Anabolic-androgenic steroids, steroid precursors, and "dietary supplements" in the United States. Journal of Sport and Social Issues, 35(1), 3-21. DOI:

$10.1177 / 0193723510396673$ 
Dunn, M., Thomas, J.O., Burns, L., Swift, W., Price, K., \& Mattick, R.P. (2009). Attitudes toward, knowledge of, and prevalence of illicit substance use in Australia: First results. Technical Report No. 305, University of New South Wales, Sydney: National Drug and Alcohol Research Centre.

Gibbons, S.L., Ebbeck, V., \& Weiss, M.R. (1995). Fair play for kids: Effects on the moral functioning of children in physical education. Research Quarterly for Exercise and Sport, 66, 247-255.

Goulet, C., Valois, P., Buist, A., \& Cote, M. (2010). Predictors of the Use of PerformanceEnhancing Substances by Young Athletes. Clinical Journal of Sport Medicine, 20(4), 243-248. doi: 10.1097/JSM.0b013e3181e0b935

Gucciardi, D.F., Jalleh, G., \& Donovan, R.J. (2011). An examination of the Sport Drug Control Model with elite Australian athletes. Journal of Science and Medicine in Sport, 14(6), 469-476. doi: 10.1016/j.jsams.2011.03.009

Hamilton, T., \& Coyle, D. (2012). The secret race: Inside the hidden world of the Tour de France: Doping, cover-ups, and winning at all costs. London, England: Bantam/Random House.

Hinds, L. (2007). Media and crime. In H. Hayes \& T. Prenzler (Eds.), An introduction to crime. (pp. 1-17). Sydney, Australia: Pearson.

Jalleh., G. \& Donovan, R. (2008). Survey of Australian elite athletes' attitudes towards and beliefs about sport issues: May 2008 Survey. Perth, Australia: Social Marketing Research Unit, School of Marketing, Curtin University.

James, R.A., Nepusz, T., Naughton, D.P., \& Petróczi, A. (2013). A potential inflating effect in estimation models: Cautionary evidence from comparing performance enhancing 
drug and herbal hormonal supplement use estimates. Psychology of Sport and Exercise, 14(1), 84-96. doi: 10.1016/j.psychsport.2012.08.003

Johnston, L. D., O'Malley, P. M., Bachman, J. G., \& Schulenberg, J. E. (2013). Monitoring the future national results on adolescent drug use. Ann Arbor, MI: Institute for Social Research, University of Michigan.

Jussim, L., \& Harber, K.D. (2005). Teacher Expectations and Self-Fulfilling Prophecies: knowns and Unknowns, Resolved and Unresolved Controversies. Personality and Social Psychology Review, 9(2), 131-155. doi: 10.1207/s15327957pspr0902_3

Kavussanu, M., \& Roberts, G.C. (2001). Moral functioning in sport: An achievement goal perspective. Journal of Sport \& Exercise Psychology, 23(1), 37-54.

Kavussanu, M., Roberts, G.C., \& Ntoumanis, N. (2002). Contextual influences on moral functioning of college basketball players. The Sport Psychologist, 16(4), 347-367.

Kavussanu, M., \& Spray, C.M. (2006). Contextual Influences on Moral Functioning of Male Youth Footballers. The Sport Psychologist, 20(1), 1-23.

Kaye, M.P., \& Boardley, I.D. (2012). Beyond punishment: Doping, deterrence, and moral disengagement. Journal of Sports Medicine and Doping Studies, 2(6). http://dx.doi.org/10.4172/2161-0673.1000e127

Kayser, B., \& Broers, B. (2012). The Olympics and harm reduction? Harm Reduction Journal, 9. doi: 10.1186/1477-7517-9-33

Kirkwood, K. (2009). Considering Harm Reduction as the Future of Doping Control Policy in International Sport. Quest, 61(2), 180-190.

Laboratory for Doping Analyses (2010). LAD statistics for year 2008. Retrieved from http://www.doping.chuv.ch/en/lad_home/lad-prestations-laboratoire/lad-prestationslaboratoire-statistiques/lad-prestations-laboratoire-statistiques-2008.htm 
Laure, P., \& Binsinger, C. (2007). Doping prevalence among preadolescent athletes: a 4-year follow-up. British Journal of Sports Medicine, 41(10), 660-663. doi:

10.1136/bjsm.2007.035733

Lippi, G., Franchini, M., \& Guidi, G.C. (2007). Tour de Chaos. British Journal of Sports Medicine, 41, 625-626.

Lucidi, F., Zelli, A., Mallia, L., Grano, C., Russo, P.M., \& Violani, C. (2008). The socialcognitive mechanisms regulating adolescents' use of doping substances. Journal of Sports Sciences, 26(5), 447-456. doi: 10.1080/02640410701579370

Madon, S., Willard, J., Guyll, M., \& Scherr, K.C. (2011). Self-fulfilling prophecies: Mechanisms, power, and links to social problems. Social and Personality Psychology Compass, 5(8), 578-590. doi: 10.1111/j.1751-9004.2011.00375.x

Merton, R.K. (1948). The self-fulfilling prophecy. Antioch Review, 8, 193-210.

Miller, D.T., \& Turnbull, W. (1986). Expectancies and interpersonal processes. Annual Review of Psychology, 37, 233-56.

Moston, S., Skinner, J., \& Engelberg, T. (2012). Perceived incidence of drug use in Australian sport: A survey of public opinion. Sport in Society, 15(1), 64-77. doi: $10.1080 / 03031853.2011 .625277$

Mottram, D.R. (2011). An introduction to drugs and their use in sport. In D. R. Mottram (Ed.), Drugs in sport (5th ed.). (pp. 3-20). New York, NY US: Routledge/Taylor \& Francis Group.

Nocelli, L., Kamber, M., Francois, Y., Gmel, G., \& Marti, B. (1998). Discordant public perception of doping in elite versus recreational sport in Switzerland. Clinical Journal of Sport Medicine, 8(3), 195-200. doi: 10.1097/00042752-199807000-00006 
Ozdemir, L., Nur, N., Bagcivan, I., Bulut, O., Sumer, H., \& Tezeren, G. (2005). Doping and performance enhancing drug use in athletes living in Sivas, mid-Anatolia: A brief report. Journal of Sports Science and Medicine, 4(3), 248-252.

Ommundsen, Y., Roberts, G. C., Lemyre, P. N., \& Treasure, D. (2003). Perceived motivational climate in male youth soccer: relations to social-moral functioning, sportspersonship and team norm perceptions. Psychology of Sport and Exercise, 4(4), 397-413. doi: 10.1016/S1469-0292(02)00038-9

Petróczi, A., \& Aidman, E. (2009). Measuring explicit attitude toward doping: Review of the psychometric properties of the Performance Enhancement Attitude Scale. Psychology of Sport and Exercise, 10(3), 390-396. doi: 10.1016/j.psychsport.2008.11.001

Petroczi, A., Aidman, E.V., Hussain, I., Deshmukh, N., Nepusz, T., Uvacsek, M., . . . Naughton, D.P. (2010). Virtue or Pretense? Looking behind Self-Declared Innocence in Doping. PLoS ONE, 5(5), e10457. doi: doi:10.1371/journal.pone.0010457

Petróczi, A., Mazanov, J., Nepusz, T., Backhouse, S.H., \& Naughton, D.P. (2008). Comfort in big numbers: Does over-estimation of doping prevalence in others indicate selfinvolvement? Journal of Occupational Medicine and Toxicology, 3, 19.

Pitsch, W., \& Emrich, E. (2011). The frequency of doping in elite sport: Results of a replication study. International Review for the Sociology of Sport, 47(5), 559-580. doi: $10.1177 / 1012690211413969$

Rees, C.R., Zarco, P.T., \& Lewis, D.K. (2007). Intermediate and high school students'attitudes toward and behavior regarding steroids and sports supplements use: The mediation of clique identity. Final Report. Montreal, Canada: WADA. 
Rest, J.R. (1984). The major components of morality. In W. Kurtines \& J. Gewirtz (Eds.), Morality, moral behavior, and moral development (pp.356-429). New York, NY: Wiley.

Rosenthal, R. (1973). On the social psychology of the self-fulfilling prophecy: Further evidence for Pygmalion effects and their mediating mechanisms. New York, NY: MSS Modular Publications.

Rosenthal, R., \& Jacobson, L. (1968). Pygmalion in the classroom: Teacher expectation and pupils' intellectual development. New York, NY: Holt, Rinehart \& Winston.

Ross, L., Greene, D., \& House, P. (1977). The false consensus effect: An egocentric bias in social perception and attribution processes. Journal of Experimental Social Psychology, 13(3), 279-301.

Schwartz, M., \& Israel, M. (2000). Born in the USA - importing American fears of random crime. Current Issues in Criminal Justice, 11, 337-342.

Smith, Aaron C. T., \& Stewart, Bob. (2008). Drug policy in sport: Hidden assumptions and inherent contradictions. Drug and Alcohol Review, 27(2), 123-129. doi: $10.1080 / 09595230701829355$

Snyder, M. (1984). When belief creates reality. In M. P. Zanna (Ed.), Advances in experimental psychology (Vol. 18, pp. 247-305). Orlando, FL: Academic Press.

Sottas, P. E., Robinson, N., Fischetto, G., Dolle, G., Alonso, J. M., \& Saugy, M. (2011). Prevalence of Blood Doping in Samples Collected from Elite Track and Field Athletes. Clinical Chemistry, 57(5), 762-769.

Spence, J.C., \& Gauvin, L. (1996). Drug and Alcohol Use by Canadian University Athletes: A National Survey. Journal of Drug Education, 26, 275-287. doi: 10.2190/V8KUCW0L-WAQH-1D3A. 
Sports Illustrated (2012). A doping free Olympics? Not in London -- and maybe never. Retrieved from http://sportsillustrated.cnn.com/2012/olympics/2012/ writers/sl_price/08/10/2012-olympics-doping/index.html\#ixzz2M3Jd4lc7

Stamm, H., Lamprecht, M., Kamber, M., Marti, B., \& Mahler, N. (2008). The public perception of doping in sport in Switzerland, 1995-2004. Journal of Sports Sciences, 26(3), 235-242. doi: 10.1080/02640410701552914

Stipis, C. (2010). The use of forensic interviewing in the fight against doping in sport. (Masters in Forensic Psychology), James Cook University, Townsville, Australia.

Striegel, H., Simon, P., Hansel, J., Niess, A. M., \& Ulrich, R. (2006). Doping and Drug Use in Elite Sports: An Analysis Using the Randomized Response Technique. Medicine and Science in Sports and Exercise, 38(5), S247-S247. doi: 10.1249/00005768200605001-01087

Striegel, H., Ulrich, R., \& Simon, P. (2010). Randomized response estimates for doping and illicit drug use in elite athletes. Drug and Alcohol Dependence, 106(2-3), 230-232. doi: 10.1016/j.drugalcdep.2009.07.026

Thomas, J.O., Dunn, M., Swift, W., \& Burns, L. (2011). Illicit drug knowledge and information-seeking behaviours among elite athletes. Journal of Science and Medicine in Sport, 14(4), 278-282. doi: 10.1016/j.jsams.2011.02.001

United States Anti-Doping Agency (2011). What sport means in America: A study of sport's role in society. Silver Spring, MD: USADA.

Verroken, M. (2000). Drug use and abuse in sport. Baillière's Best Practice \& Research. Clinical Endocrinology \& Metabolism, 14(1), 1-23.

Waddington, I., Malcolm, D., Roderick, M., \& Naik, R. (2004). Drug use in English professional football. British Journal of Sport Medicine, 39, e18. 
Wiefferink, C. H., Detmar, S. B., Coumans, B., Vogels, T., \& Paulussen, T. G. W. (2008). Social psychological determinants of the use of performance-enhancing drugs by gym users. Health Education Research, 23(1), 70-80. doi: 10.1093/her/cym004

World Anti-Doping Agency (2003). World Anti-Doping Code. Montreal, Canada: World Anti-Doping Agency. Retrieved from http://www.wada-ama.org/

World Anti-Doping Agency (2009). World Anti-Doping Code. Montreal, Canada: World Anti-Doping Agency. Retrieved from http://www.wada-ama.org/

World Anti-Doping Agency (2012). 2011 laboratory testing figures. Retrieved from http://www.wada-ama.org/Documents/Resources/Testing-Figures/WADA-2011Laboratory-Testing-Figures.pdf 
Table 1

Demographic Characteristics of Respondents and Mean Moral Functioning

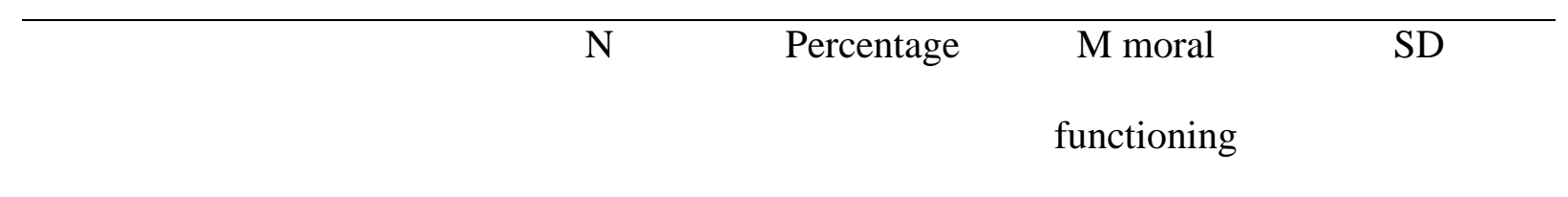

Gender

$\begin{array}{lrrrr}\text { Male } & 134 & 42.95 & 1.74 & .56 \\ \text { Female } & 178 & 57.05 & 1.67 & .48\end{array}$

Age Group

$\begin{array}{lcccc}12-13 \text { years } & 100 & 32.05 & 1.70 & .48 \\ 14-15 \text { years } & 97 & 31.09 & 1.71 & .53 \\ 16-17 \text { years } & 115 & 36.86 & 1.69 & .54\end{array}$

Involvement in Sport

$\begin{array}{lcccc}\text { Non-athletes } & 163 & 52.24 & 1.69 & .54 \\ \text { Athletes } & 149 & 47.76 & 1.71 & .50\end{array}$


Table 2

Perceived Incidence of PED use by Respondent Demographics

\begin{tabular}{cccc}
\hline & N & M & SD \\
\hline Gender & 134 & 25.39 & 21.45 \\
Male & 178 & 31.44 & 19.43 \\
Female & & & \\
Age Group & 100 & 33.52 & 19.87 \\
12-13 years & 97 & 31.08 & 22.33 \\
14-15 years & 115 & 22.89 & 18.04 \\
16-17 years & & & 19.54 \\
Involvement in Sport & 163 & 30.16 & 21.49 \\
Non-athletes & 149 & 27.40 & \\
Athletes & & & \\
\hline
\end{tabular}


Table 3

Frequency of Estimates of Incidence of PED use

\begin{tabular}{lll}
\hline Estimated Incidence of & $\mathrm{N}$ & $\%$
\end{tabular}

PED use (per cent)

\begin{tabular}{llc}
\hline 0 & 2 & 0.64 \\
1 to 10 & 36 & 11.54 \\
11 to 20 & 62 & 19.87 \\
21 to 30 & 64 & 20.51 \\
31 to 40 & 56 & 17.95 \\
41 to 50 & 29 & 9.29 \\
51 to 60 & 24 & 7.69 \\
61 to 70 & 23 & 7.37 \\
71 to 80 & 7 & 2.24 \\
81 to 90 & 5 & 1.60 \\
$91-100$ & 4 & 1.28 \\
\hline
\end{tabular}

